\title{
Salvando el ojo: Queratitis bacteriana complicada en León africano (Panthera leo), manejo con Medicina Biorreguladora. Reporte de caso
}

\author{
Natalia Agudelo ${ }^{1}$ \\ Corresponding Author: Natalia Agudelo, nagudelo@parquejaimeduque.com.co \\ 1 nagudelo@parquejaimeduque.com.co
}

\begin{abstract}
La queratitis bacteriana se entiende como una infección causada por bacterias que infectan la capa más superficial de la córnea, alterando la integridad de ésta provocando dolor, incomodidad, opacidad corneal, pérdida de visión y en casos graves la perforación ocular y pérdida del globo ocular si no es tratada a tiempo. Esta patología en felinos silvestres y específicamente en León africano (Panthera leo) ha sido poco estudiada y existen pocas publicaciones relacionadas, por lo que existe un vacío en el conocimiento respecto a similitud o diferencias de esta patología en comparación con felinos domésticos y otros mamíferos. Así mismo, respecto a las posibilidades terapeúticas desde la medicina alópatica y alternativa, sabiendo de antemano que son animales que representan un riesgo para las personas que los manejan. Este es el caso de una Leona africana (Panthera leo) de más de 12 años de edad (geronte), que se encuentra bajo el cuidado humano en un Bioparque colombiano que en agosto de 2018 presento una luxación anterior de cristalino en su ojo izquierdo por lo que tuvo que ser intervenida quirúrgicamente por la oftalmóloga; posterior a esto presentó algunas complicaciones, entre ellas una inadecuada cicatrización y úlceras corneales intermitentes por lo que su córnea se tornó opaca con el tiempo. A comienzos del 2020 la leona venia con tratamiento oftálmico para aclarar la córnea y se evidenció una zona deprimida en el centro de la córnea por lo que se sospechó de úlcera corneal (Ojo izquierdo) y se inicia tratamiento con suero heterólogo Tópico; posterior a esto, la leona inicia con signos compatibles con Queratitis bacteriana complicada que pudo ser confirmada días después. Pese al tratamiento antibiótico instaurado al inicio y el control inicial de la infección, la córnea se evidenciaba muy opaca, deforme con una marcada neovascularización y amenazando con la pérdida de su integridad y el riesgo de perder el globo ocular. Conforme a esto se adiciona al tratamiento medicamentos Biorreguladores que permitieron acelerar el control de la infección y modular de tal manera el proceso inflamatorio y de cicatrización que la córnea al final se observó más clara que como estaba previamente antes del desarrollo de esta patología evidenciado remodelación completa del tejido corneal y desaparecieron todos los vasos sanguíneos en la córnea de la Leona permitiendo que a los 3 meses la cornea ya no tuviera protuberancias, deformaciones y sanara por completo la lesión central y a los 6 meses desaparecieran todos los vasos sanguíneos sobre la córnea devolviendo visión y estética de la Leona. Todo este proceso se logró gracias a lo que se conoce desde la etología como condicionamiento operante con refuerzo positivo implementado por el área de salud comportamental del Bioparque, lo que permitió que la Leona
\end{abstract}


se dejara aplicar el tratamiento a voluntad sin necesidad de anestesiarla y sin colocar en riesgo al personal. En la actualidad la Leona continúa con tratamiento Biorregulador para lograr aclarar aún más la córnea. Conforme a todo lo anterior, este caso motiva a continuar generando conociemiento en el tratamiento de patologías oculares con el uso de medicamentos Biorreguladores.

Keywords: Queratitis bacteriana, medicina biorreguladora, animales silvestres.

\section{Introduction}

El león africano (Panthera leo) es de los felinos silvestres más grandes del mundo (1). Así mismo esta especie se encuentra en estado vulnelabre de conservación según la UICN (2). Bajo el cuidado humano, los leones son considerados una especie embajadora y son mantenidos con fines turísticos, educativos y de conservación (3). En este sentido, para las instituciones que tienen estos animales bajo su cuidado es de vital importancia generar conocimiento que permita entender de una mejor manera el comportamiento y los procesos patológicos y la viabilidad y efectividad de los tratamientos médicos, que comunmemte se convierte en un reto para la medicina de fauna silvestre.

La queratitis bacteriana se entiende como una infección causada por bacterias de diferentes tipos que infectan la capa más superficial de la córnea, alterando la integridad de ésta pudiendo provocar dolor, incomodidad, opacidad corneal, pérdida de visión y en casos graves la perforación ocular y pérdida del globo ocular si no es tratada a tiempo (4). Esta patología en felinos silvestres y específicamente en Panthera leo ha sido poco estudiada y existen muy pocas publicaciones realcionadas, por lo que existe un vacío en el conociemiento respecto a similutud o diferencias de esta patología en comparación con felinos domésticos y otros mamíferos. Así mismo, con respecto a sus posibilidades terapeúticas y manejo sabiendo de antemano que son animales que representan un riesgo para las personas que los manejan.

En medicina humana y medicina de pequeños animales la información sobre esta patología es similar en cuanto al diagnóstico y tratamiento desde la alopatía, en donde el manejo terapeútico convencional se basa en el uso de analgesia, antibióticos tópicos y sistémicos con un cultivo y antibiograma previo al tratamiento para una oportuna escogencia del antibiótico y evitar la complicación más común que es la perforación corneal con las consecuencias que ésto implica como perdida de visión, opacidad corneal, deformación corneal, entre otras (5-10). Este tipo de complicaciones se convierten en una de las limitantes de este tipo de patología adicionando a esto, el poco conocimiento que existe al respecto de las opciones terapeúticas alternativas en el caso de las queratitis bacterianas que puedan por un lado evitar de una mejor manera estas complicaciones y por el otro acelerar el proceso de recuperación.

\section{Timeline}


Viene con tratamiento (Ciclosporina 1 y 2\%, Oq-caps, solución salina hipertónica) por opacidad corneal severa secundaria a un proceso cicatrizal por una cirugía para corrección de luxación anterior de cristalino en el 2018. Ojo izquierdo.

Se le hace control por la oftalmóloga ya que se evidencia una zona deprimida en el centro de la córnea. Se sospecha de úlcera corneal (Ojo izquierdo) por lo que se inicia tratamiento con suero heterólogo Tópico BID HNO. Imagen 1 visual en el ojo afectado.

Se inicia tratamiento con suero heterólogo en ojo izquierdo BID HNO.

Se sospecha de queratitis bacteriana. Se instaura tratamiento con Tobramicina oftálmica 2 gotas en el ojo afectado BID 5 min después del suero.

Se adiciona al tratamiento: Moxifloxacino en ojo afectado BID HNO, Trimetroprim sulfametoxazol DB: $30 \mathrm{mg} / \mathrm{kg}$ PO SID x 10 D inicialmente y Meloxicam DB: $0.3 \mathrm{mg} / \mathrm{kg}$ el primer día y luego DB:0.1 mg/kg PO SID x 5D. Se suspende suero heterólogo.

Se revisa presencialmente (ojo izquierdo): se observa una marcada secreción purulenta adherida a la córnea, al parecer hay úlcera corneal profunda y proceso inflamatorio severo. Imagen 4 
2020-04-03 — Ha venido mejorando y la infección en la córnea ha cedido bastante. Sin embrago preocupa el proceso inflamatorio y que la córnea se encuentra irregular y con la parte central débil por lo que preocupa que se perfore.

Se inicia tratamiento con Medicina Biorreguladora: $0.2 \mathrm{ml}$ Traumeel ad us. vet. ampollas $+0.2 \mathrm{ml}$ Flamosin compositum ad us. vet. ampollas $+0.2 \mathrm{ml}$ Placenta compositum ampollas en la misma jeringa del antibiótico BID. queda con los Biorreguladores y se evidencia una marcada neovascularización en la córnea. Imagen 5 y 6

Ha venido evolucionando muy bien la parte central de la córnea está cubierta por completo de tejido vascular. Imagen 7-9

Termina tratamiento con Flamosin compositum ad us. vet. ampollas y Placenta compositum ampollas. Cambia a $0.5 \mathrm{ml}$ de Traumeel ad us. vet. ampollas x $10 \mathrm{D}$.

Se realiza en común acuerdo con la oftalmóloga test de fluoresceína, resulta negativa y se evidencia que la córnea se está remodelando y sanando muy bien. Se modifica tratamiento a Traumeel ad us. vet. ampollas $0.5 \mathrm{ml}$ SID. Imagen 10

Se modifica tratamiento a $0.2 \mathrm{ml}$ de Ciclosporina $1 \%+0.3 \mathrm{ml}$ de Traumeel ad us. vet. BID por indicación de oftalmóloga. 
2020-06-10 - Se realiza control y Test de fluoresceína y sale negativo. Sin embargo la córnea no está aclarando como se esperaba. Se cambia nuevamente a Ciclosporina 1\% $0.2 \mathrm{ml}+$ Traumeel ad us. vet. ampollas $0.3 \mathrm{ml}$ en común acuerdo con la oftalmóloga.

Se cambia nuevamente la Ciclosporina $1 \%$ por la Prednisolona Acetato $1 \%$ por costos.

Se observa que la córnea está aclarando un poco más. Se evidencia que no ha recuperado capacidad visual en el ojo afectado.

El ojo ha presentado una excelente evolución. La córnea aclaró un poco y está completamente remodelada y lisa. Se propone a oftalmóloga suspender prednisolona y continuar sólo con Traumeel ad us. vet. ampollas $0.5 \mathrm{ml}$ en ojo izquierdo SID HNO y acepta.

Se realiza control y se observa muy bien. Continúa con el último tratamiento.

Se realiza control y se observa muy bien. Se evidencia que la leona ha recuperado capacidad visual en el ojo afectado. Continúa con el mismo tratamiento. Imagen 12

Se realiza control y se modifica tratamiento a $0.5 \mathrm{ml}$ de Traumeel ad us. vet. ampollas una vez por semana HNO. sanguíneos y se evidencia que está más clara que cuando se estaba realizando tratamiento con Prednisolona. Se le alcanza a ver la pupila. Continúa tratamiento. 


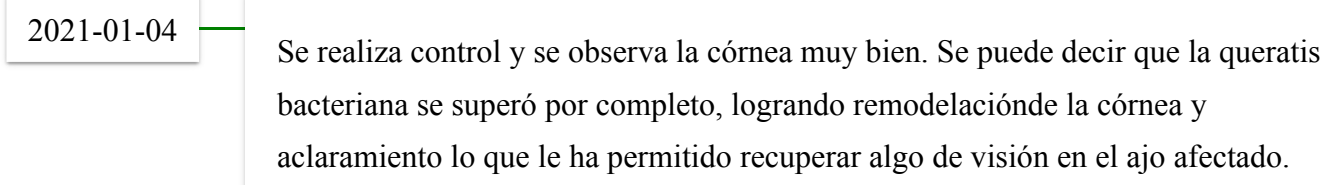

2021-01-30 - Se evidencia una mejoría muy notoria en la capacidad visual donde es capaz de percibir movimientos y acercamiento al ojo afectado, por este motivo se dificulta un poco el tratamiento.

\section{Narrative}

Una leona africana (Panthera leo) de más de 12 años de edad (geronte), que se encuentra bajo el cuidado humano en un Bioparque colombiano ya que no puede volver a la libertad. Fue decomisada en el 2008 ya que la tenían en un circo en la ciudad de Bogotá en condiciones inadecuadas. En agosto de 2018 presento una luxación anterior de cristalino en su ojo izquierdo por lo que tuvo que ser intervenida quirúrgicamente por la oftalmóloga de cabecera; posterior a esto presentó algunas complicaciones, entre ellas una inadecuada cicatrización y úlceras corneales intermitentes por lo que su córnea se tornó opaca con el tiempo. A comienzos del 2020 la leona venia con tratamiento oftálmico para aclarar la córnea lo más posible con ciclosporina de $1 \%$ y $2 \%$, Oq-caps $(\mathrm{R})$ y solución salina hipertónica. El 11 de marzo de 2020. Se le hace control por la oftalmóloga de cabecera ya que se evidencia una zona deprimida en el centro de la córnea (Imagen 1). Se sospecha de úlcera corneal (Ojo izquierdo) por lo que se inicia tratamiento con suero heterólogo Tópico BID HNO. EI 19 de marzo de 2020 se reporta que la leona presenta secreción mucosa en el ojo afectado (izquierdo) y mayor opacidad (Imagen 2); no fue posible la valoración presencial por la situación sanitaria del país y del mundo por COVID-19 que obligó a cerrar el Parque y a reducir el personal en trabajo presencial el cual se estaba realizando de manera esporádica en ese momento; el 23 de marzo de 2020 se solicita foto a los cuidadores (Imagen 3), se evidencian cambios compatibles con 
queratitis bacteriana por lo que se instaura tratamiento con Tobramicina oftálmica 2 gotas en el ojo afectado BID 5 min después del suero; 6 días después ( 25 de marzo de 2020) que es posible ir al Bioparque y se evidencia que la leona presenta en el ojo izquierdo una marcada secreción purulenta adherida a la córnea, al parecer hay úlcera corneal profunda ya que el test de fluoresceína resulta negativo para úlcera superficia y un proceso inflamatorio severo (Imagen 4). Por lo que se diagnostica Queratitis bacteriana complicada. Por lo anterior, se adiciona al tratamiento con suero heterólogo, Moxifloxacino en ojo afectado BID HNO, se inicia Trimetoprim sulfametoxazol DB: $30 \mathrm{mg} / \mathrm{kg}$ PO SID x 10 D inicialmente y Meloxicam DB: 0.3mg/kg el primer día y luego a DB:0.1 mg/kg x 5 D consecutivos y la oftalmóloga de cabecera confirma diagnóstico y avala el tratamiento a distancia.

Desde que la leona inicia el tratamiento hasta el $\mathbf{0 3}$ de abril de 2020 ha venido mejorardo y la infección en la córnea está controlada. Sin embrago preocupa el proceso inflamatorio severo y que la córnea se encuentra irregular, con protuberancias y con la parte central débil por lo que preocupa que se perfore.

Termina antibiótico oral, continúa con Moxifloxacino tópico HNO y se inicia tratamiento con Medicina Biorreguladora: $0.2 \mathrm{ml}$ Traumeel ad us. vet. ampollas $+0.2 \mathrm{ml}$ Flamosin compositum ad us. vet. ampollas $+0.2 \mathrm{ml}$ Placenta compositum ampollas en al misma jeringa del antibiótico BID, esto con el fin de modular el proceso inflamatorio, favorecer una adecuada cicatrización y evitar que la córnea se perfore.

El 10 de abril de 2020 la queratitis bacteriana está controlada (Imagen 5 y 6). Se suspende el antibiótico tópico. sólo queda con los Biorreguladores y se evidencia una marcada neovascularización; entre el 11 y 24 de abril de 2020 se observa que los vasos sanguíneos en la córnea que trata de rodear la lesión central descrita anteriormente (Imagen 7 y 8). Entre el 25 y 27 de abril de 2020 se evidencia que ha venido evolucionando muy bien, la parte central de la córnea está cubierta por completo de tejido vascular (Imagen 9). Termina tratamiento con Flamosin compositum ad us. vet. ampollas y Placenta compositum ampollas. Cambia a $0.5 \mathrm{ml}$ de Traumeel ad us. vet. ampollas $x 10 \mathrm{D}$ BID con el fin de modular la neivascularización e intentar que estos vasos sanguíneos desaparezcan y para poder iniciar a aclarar la córnea con Ciclosporina (según la indicación de la oftalmóloga).

El 8 de mayo de 2020 se realiza en común acuerdo con la oftalmóloga, el test de fluoresceína, resulta negativo y se evidencia que la córnea se está remodelando y sanando muy bien no se observan irregularidades en la misma (Imagen 10). Se cambia tratamiento a Traumeel ad us. vet. ampollas $0.5 \mathrm{ml}$ SID HNO. EI 21 de mayo de 2020 Se modifica el tratamiento a $0.2 \mathrm{ml}$ de Ciclosporina 1\% + $0.3 \mathrm{ml}$ de Traumeel ad us. vet. BID por indicación de oftalmóloga para iniciar a aclarar la córnea. El $\mathbf{2 4}$ de mayo de $\mathbf{2 0 2 0}$ se realiza control presencial y se observa que la córnea está muy bien y continúa aclarando por lo que continúa el mismo tratamiento.

Entre el 4 y 5 de junio de 2020 se realiza Test de fluoresceína de control y resulta negativo para úlcera superficial. Adicionalmente, se cambia tratamiento con prednisolona acetato $1 \% 0.2 \mathrm{ml}+0.3$ $\mathrm{ml}$ de Traumeel BID, por los costos del tratamiento y situación financiera del Parque por la Pandemia y éste es avalado por la oftalmóloga. El tratamiento es por $5 \mathrm{D}$ inicialmente y luego se 
valorará respuesta a la predinosolona. El 10 de junio de 2020 se realiza control y Test de fluoresceína y sale negativo. Sin embargo la córnea no está aclarando como se esperaba por lo que se cambia nuevamente a Ciclosporina $1 \% 0.2 \mathrm{ml}$ + Traumeel ad us. vet. ampollas $0.3 \mathrm{ml}$ en común acuerdo con la oftalmóloga y la gerencia el Parque, para valorar si aclara mejor la córnea con éste tratamiento. El 18 de junio de 2020 se cambia nuevamente la Ciclosporina 1\% por la Prednisolona Acetato 1\% por costos y el 20 de Junio de 2020 se observa que la córnea ha aclarado un poco más. Continúa con el Traumeel ad us. vet. Ampollas $0.3 \mathrm{ml}$ BID, en el ojo izquierd HNO.

El 3 de julio de 2020 se realiza control y el ojo ha presentado una excelente evolución. La córnea aclaró un poco más y está completamente remodelada y lisa (Imagen 11). Se propone a oftalmóloga suspender prednisolona y continuar sólo con Traumeel ad us. vet. ampollas $0.5 \mathrm{ml}$ en ojo izquierdo SID HNO y se acepta la propuesta.

El 17 de julio y 4 de septiembre de 2020 se realiza control y se observa muy bien (Imagen 12). Continúa con el último tratamiento.

El 13 de octubre de 2020 se realiza control y se modifica tratamiento a $0.5 \mathrm{ml}$ de Traumeel ad us. vet. ampollas una vez por semana HNO.

El 18 de noviembre de 2020 se realiza control; se observa que la córnea continua lisa, sin protuberancias, humectada y sin vasos sanguíneos y se evidencia que está más clara que cuando se estaba realizando tratamiento con Prednisolona. Se le alcanza a ver la pupila. Continúa tratamiento.

El 4 de enero de 2021 se realiza control y se observa la córnea muy bien. Se puede decir que la queratis bacteriana se superó por completo, logrando remodelación de la córnea y. aclaramiento lo que le ha permitido a la leona recuperar algo de visión en el ajo afectado.

El 10 de enero de 2021 se realiza control y se evidencia la córnea un poco más clara, sobre todo, en la parte medial de la córnea (Imagen 13). Continúa con Traumeel ad us. vet. Ampollas 0.5 ml en ojo izquierdo SID HNO. El 16 de Enero de 2020 se suspende el Traumeel ad us. vet. ampollas y se inicia tratamiento $0.2 \mathrm{ml}$ de Gallium-Heel $\mathrm{N}$ ampollas $+0.2 \mathrm{ml}$ de Lymphomyosot $\mathrm{N}$ ampollas y $0.2 \mathrm{ml}$ de Ubichinon compositum ampollas en el ojo izquierdo BID 3 veces por semana durante dos semanas inicialmente para aclarara aún más la córnea. Este tratamiento es avalado por la oftalmóloga.

El 30 de enero de 2021 se observa que la córnea ha aclarado aún más y está tomando un color azuloso (Imagen 14) por lo que continuará con el último tratamiento instaurado SID 3 veces por semana HNO.

Todo este proceso se ha realizado por medio de condicionamiento operante implemenrdo por el area de salud comportamental donde la leona permite aplicar las gotas a voluntad.

\section{Perspective}


Cuando la leona inició con la patología se veía con dolor, bastante incomodidad es su cara y estresada y no le gustaba el tratamiento ya que las gotas de antibiótico, Ciclosporina y Prednisolona le ardían, una vez se controla la infección y empieza a remodelarse la córnea con la Medicina Biorreguladora se observa que la leona está más tránquila, ya no presenta singnos de dolor e imcomodidad y cuando se empezó a manejar sólo el Traumeel la leona empieza a disfrutar el tratamiento ya que obtiene un refuerzo positivo y no le arde cada vez que se realiza.

\section{Discussion}

A pesar de que existe muy poca información respecto a la queratitis bacteriana en felinos silvestres y leones específicamente, ésta patología ha sido estudiada de una manera más profunda en animales domésticos y mucho más en humanos y el manejo terapeútico convencional se basa en el uso de analgesia, antibióticos tópicos y sistémicos con un cultivo y antibiograma previo al tratamiento para una oportuna escogencia del antibiótico y evitar la complicación más común que es la perforación corneal con las consecuencias que ésto implica como perdida de visión, opacidad corneal, deformación corneal, entre otras (5-10). En el caso de la leona no fue posible realizar cultivo y antibiograma previo debido a la situación sanitaria mundial por COVID-19 que afectó de manera considerable el estado financiero y el personal del Bioparque. Sin embargo, se escogió un antibiótico de amplio espectro como la tobramicina de uso oftálmico y Trimetoprim Sulfametoxazol por vía oral y que eran los antibióticos que se se tenían disponibles para controlar lo más rápido posible la infección bacteriana en la córnea, y posteriormente se pasa a Moxifloxacino ya que éste es uno de los antibióticos de elección para patologías bacterianas oculares complicadas y se evidenció una mejor respuesta a este antibiótico $(11,12)$. Cabe resaltar que los antibióticos sólo se utilizaron en la fase inicial para el control de la infección y una vez logrado esto se realizó tratamiento con Medicina Biorreguladora para modular la inflamación, dolor y promover la remodelación corneal.

Revisando la literatura existen muy pocos estudios en lo que se refiere al manejo de esta patología desde la medicina Biorreguladora y alternativa (13), incluso existen algunos estudios que postulan el uso de medicinas alternativas como un factor predisponente para el desarrollo de ésta patología, haciendo especial referencia al uso de productos naturales que pueden ser irritantes y abrasivos para la córnea (14), por lo que este reporte de caso podría extrapolarse a otras especies incuido el hombre y al mismo tiempo genera la necesidad de generar nuevo conocimiento en relación a esta patología y similares desde la Medicina Veterinaria y Medicina humana.

Con respecto al la utilización de suero heterólogo (autólogo), éste está indicado para el tratamiento de úlcera corneal (15). Sin embargo una contaminación de este pudo haber sido la fuente de infección corneal en este caso, pero no se pudo comprobar por la situación sanitaria nacional y mundial del momento que no permitió realizar las acciones pertinentes en el momento.

En relación a la utilización de lo medicamentos Biorreguladores se puede decir que, en primer lugar se escogió la presentación en ampollas para todos los medicamentos para poder aplicarlo de manera tópica sobre la córnea sin generar daño en el tejido e incomodidad en el paciente por los vehículos y o bases de los medicamentos. En el caso específico del Traumeel ad us. vet. ampollas se escogió desde el inicio de la terapia con el fin de modular la respuesta inflamatoria severa a la infección y ésto a su vez contribuye de manera positiva al manejo del dolor ocular, ésto gracias a su efecto sobre 
la modulación de las vías tanto proinflamatorias como antiinflamatorias para recuperar y mantener la homeostasis, en lugar de su supresión. Además Traumeel ${ }^{\circledR}$ actúa para corregir los efectos de la inflamación en los tejidos del organismo (16); Este medicameno se dejó sólo por un tiempo con el fin de que continuara modulando el proceso inflamatorio y de cicatrización de la córnea. Para el caso del Flamosin compositum ad us. vet. ampollas se utilizó con el propósito de modular y reparar la mucosa conjuntival (18) y la Placenta compositum ampollas para estimular y modular la vascularización $(17,18)$ que se generó por el proceso inflamatorio e infeccioso y éste contribuyera a la reparación de la córnea que estaba ulcerada y con deformaciones. Una vez logrado todo esto y observando que la córnea cicatrizó de manera adecuada remodelandose el tejido córneal y mejorando la opacidad que tenía la leona antes de desarrollar la queratitis bacteriana se decide iniciar tratamiento con Galium-Heel N ampollas, Lymphomyosot $\mathrm{N}$ ampollas y Ubichinon compositum ampollas $(17,19)$ con el fin de buscar aclarar aún más la córnea por medio de la detoxificación profunda y drenaje de la matriz corneal, buscando desbloquear los procesos enzimáticos en la matriz corneal que se alteraron en el proceso de cicatrización (19); así se haya modulado con Traumeel (R) se quiso indagar si era posible aclarar la córnea aún más lo cual se logró y por tal motivo la leona continuó con este último tratamiento hasta nueva orden.

Conforme a lo anterior, Se pudo evidenciar en todo el proceso que la queratitis bacteriana complicada en la Leona evolucionó de una manera exitosa evitando la perforación corneal con la sinergia de medicamentos alopáticos (antibióticos tópicos y sistémicos) y Biorreguladores (Traumeel ad us. vet. ampollas, Flamosin compositum ad us. vet. ampollas y Placenta compositum). Adicional a esto, se observó con sorpresa que se logró la modulación de la vascularización sobre la córnea con los medicamentos biorreguladores mencionados en el párrafo anterior y cómo esta se enfocó en rodear la parte central de la cornea (la que estaba más débil) en 2 meses de tratamiento, permitiendo que la córnea sanara de manera exitosa y se remodelara todo el tejido para terminar siendo una córnea lisa y humectada nuevamente. En este sentido es importante mencionar que el tratamiento con antibiótico y con Biorreguladores fueron en tiempos distintos (como se muestra en la línea de tiempo).

Adicionalmente, se observó cómo posteriormente se terminó de modular todo el proceso inflamatorio y de vascularización en 6 meses, con Traumeel ad us. vet en el ojo afectado . ampollas, permitiendo que sobre la córnea no quedaran vasos sanguíneos, finalizando con un aclaramiento inesperado de la córnea, por la acción de Traumeel ad us. vet ampollas sólo por 3 meses, que luego fue mayor el aclaramiento de la córnea con la suspensión del Traumeel (R) y el uso de Gallium-Heel $\mathrm{N}$ ampollas, Lymphomyosot $\mathrm{N}$ ampollas y de Ubichinon compositum ampollas que mejoró la capacidad visual (este aspecto se doscutirá más adelante) y la estética de la leona sin necesidad de colocar en riesgo el tejido corneal por inmunosupresión excesiva que podría aumentar la suceptibilidad a infecciones futuras entre otros efectos indeseables, como podría suceder con el uso prolongado medicamentos como la ciclosporina (20) y prednisolona (21). Con respecto a lo anterior, cabe resaltar que durante todo el proceso post remodelación corneal hubo intercambios constantes entre el uso de la ciclosporina y la prednisolona oftálmica, ya que la intención de la oftálmóloga era buscar aclarar la córnea con alguno de estos medicamentos y se evaluó con estos usos alternantes cuál funcionaba mejor en el cumplimiento del objetivo, con lo cual se evidencia que no hay cambios entre los dos medicamentos sobre la opacidad de la córnea y por este motivo se decide suspender su 
aplicación para evitar los efectos secundarios ya mencionados $(20,21)$ y teniendo en cuenta la evolución satisfactoria que hubo en todo el proceso de modulación del proceso inflamatorio y remodelación de la cornea ocurrido con el uso de medicamentos biorreguladores.

Para el caso de la valoración de la capacidad visual no existen parámetros claros para la valoración de la misma en animales silvestres y en este caso específico para leones. Sin embargo existen comportamientos y señales en el rostro que permiten identificar si el animal tiene la capacidad de ver por un ojo u otro (22). En este caso, al inicio del proceso, incluso antes de iniciar con el cuadro de queratirtis bacteriana, la leona presentaba una opacidad corneal marcada (como se describió en la narrativa), que le había afectado la capacidad visual por completo, es decir el animal no mostraba signos de alerta, defensa y expresiones faciales cuando el personal del Bioparque se acercaba por el ojo afectado. En este sentido, una vez logrado el objetivo "inesperado" de aclarar la córnea con los medicamentos biorreguadores se observa en la leona que recupera algo de capacidad visual ya que vuelve a tener expresiones de amenaza, defensa cuando el personal se acerca por el ojo afectado.

En consecuencia, se puede afirmar que el exito del tratamiento instaurado en la leona estuvo relacionado con el uso de medicamentos biorreguladores junto con el uso de la antibioticoterapia (esto no quiere decir que el tratamiento biorregulador sea un complemento de la antibioticoterapia sino que por el contrario ambos tratamientos actuaron sinérgicamente como ya se mencionó y cada uno fue implementado con objetivos y tiempos diferentes) y en el caso específico de la modulación el proceso inflamatorio y la remodelación corneal se dió por la acción de los medicamentos biorreguladores y no por la prednisolona y ciclosporina, ya que estos se utilizaron después de este proceso con el fin de buscar aclarar más la córnea.

Finalmente, Este caso motiva a continuar generando conocimiento en el tratamiento de patologías oculares con el uso de medicamentos Biorreguladores de Heel en presentación de ampollas de manera tópica.

\section{$\underline{\text { Conclusion }}$}

- Se pudo controlar la queratitis bacteriana complicada en la Leona de una manera exitosa evitando la perforación corneal con la sinergia de medicamentos alopáticos (antibióticos tópicos y sistémicos) y Biorreguladores (Traumeel ad us. vet. ampollas, Flamosin compositum ad us. vet. ampollas y Placenta compositum).

- Se observó con sorpresa que se logró la modulación de la vascularización sobre la córnea con los medicamentos biorreguladores mencionados en el párrafo anterior y cómo esta se enfocó en rodear la parte central de la cornea (la que estaba más débil) en 2 meses de tratamiento, permitiendo que la córnea sanara de manera exitosa y se remodelara todo el tejido para terminar siendo una córnea lisa y humectada nuevamente.

- Se observó cómo posteriormente se terminó de modular todo el proceso inflamatorio y de vascularización en 6 meses, con Traumeel ad us. vet ampollas en el ojo afectado, permitiendo que sobre la córnea no quedaran vasos sanguíneos, finalizando con un aclaramiento inesperado de la córnea, por la acción de Traumeel ad us. vet ampollas sólo por 3 meses, que 
luego fue mayor el aclaramiento de la córnea con la suspensión del Traumeel (R) y el uso de Gallium-Heel $\mathrm{N}$ ampollas, Lymphomyosot $\mathrm{N}$ ampollas y de Ubichinon compositum ampollas que mejoró la capacidad visual y la estética de la leona sin necesidad de colocar en riesgo el tejido corneal por inmunosupresión excesiva que podría aumentar la suceptibilidad a infecciones futuras entre otros efectos indeseables, como podría suceder con el uso prolongado medicamentos como la ciclosporina (20) y prednisolona (21) .

- Este caso motiva a continuar generando conociemiento en el tratamiento de patologías oculares con el uso de medicamentos Biorreguladores de Heel en presentación de ampollas de manera tópica.

\section{$\underline{\text { Acknowledgements }}$}

Agradezco a la gerencia de Parque Jaime Duque y la Dirección y equipo técnico del Bioparque Wakatá por la confianza y el apoyo para la realización de este tipo de tratamientos con los animales del Bioparque, a los cuidadores y estudiantes por el compromiso con el tratamiento de la leona y su seguimiento y a la oftalmóloga de cabecera (Dra. Andrea Mora) por su acompañamiento y apoyo.

\section{$\underline{\text { References }}$}

1. Nobuyuki Yamaguchi, Alan Cooper, Lars Werdelin and David W. Macdonald (2004). Evolution of the mane and group-living in the lion (Panthera leo): a review. Journal of Zoology, Volume 263, Issue 4. Publicado en línea el 28 de febrero de 2006.

2. Bauer, H., Packer, C., Funston, P.F., Henschel, P. \& Nowell, K. 2016. Panthera leo (errata version published in 2017). The IUCN Red List of Threatened Species 2016:

e.T15951A115130419. https://dx.doi.org/10.2305/IUCN.UK.2016-

3.RLTS.T15951A107265605.en. Downloaded on 12 January 2021.

3. Dollinger P, Geser S. Animals: WAZA'S virtual zoo - lion. WAZA'S virtual zoo. WAZA (World Association of Zoos and Aquariums). Archivado desde el original el 29 de septiembre de 2011. Consultado el 7 de diciembre de 2009.

4. Martín Navarro et al . The potential pathogenicity of chlorhexidine-sensitive Acanthamoeba strains isolated from contact lens cases from asymptomatic individuals in Tenerife, Canary Islands, Spain. Journal of Medical Microbiology 200857 (11): 1399-1404. doi:10.1099/jmm.0.2008/003459-0. Consultado el 8 de enero de 2021.

5. Mary E. Marquart (2011). Animal Models of Bacterial Keratitis. Review Article. Journal of Biomedicine and Biotechnology, Article ID 680642, 12 pages doi:10.1155/2011/680642. Consultado el 10 de enero de 2021.

6. Muhammet Karakavuk et al. First time identification of Acanthamoeba genotypes in the cornea samples of wild birds; Is Acanthamoeba keratitis making the predatory birds a target?. Exp Parasitol Dec 2017;183:137-142. doi: 10.1016/j.exppara.2017.08.007. Epub 2017 Aug 12. Cosultado el 10 de Enero de 2021.

7. Giuseppina Gelormini, Dominique Gauthier, Edy M. Vilei, Jean Paul Crampe, Joachim Frey, Marie Pierre Ryser. DegiorgisInfectious keratoconjunctivitis in wild Caprinae: merging field observations and molecular analyses sheds light on factors shaping outbreak dynamics. $B M C$ 
Vet Res. 2016; 13: 67. Published online 2017 Mar 4. doi: 10.1186/s12917-017-0972-0.

Consultado el 10 de enero de 2021.

8. C. M. H. Colitz et al. (2010). Characterization of "Sea Lion Keratitis" in Captive Zalophus Californianus: Descriptive Analysis. ARVO. Investigative Ophthalmology \& Visual Science April 2010, Vol.51, doi:5722. Consultado el 10 de enero de 2021.

9. Singaretti de Oliveira, Fabrício, de Almeida, Denise Eliza, Mendes Vicenti, Felipe Antônio, Fernandes Machado, Márcia Rita, Canola, Júlio Carlos. Ulcerative keratitis in paca (Agouti paca). Acta Scientiae Veterinariae [en linea]. 2009, 37(4), 401-403 ISSN: 1678-0345.

Disponible en: https://www.redalyc.or /articulo.oa?id=289021855017. Consultado el 18 de enero de 2021.

10. Majid Moshirfar et al. Biological Staining and Culturing in Infectious Keratitis: Controversy in Clinical Utility. Med Hypothesis Discov Innov Ophthalmol. 2019 Autumn; 8(3): 145-151. Disponible en: https://www.ncbi.nlm.nih.gov/pmc/articles/PMC6778464/. Consultado el 18 de enero de 2021.

11. Jean Deschênes. Bacterial Keratitis Treatment \& Management (2019). Medscape. Disponible en: https://emedicine.medscape.com/article/1194028-treatment. Consultado el 8 de enero de 2021.

12. Elissa M McDonald, Felix S F Ram, Dipika V Patel, Charles N J McGhee. Topical antibiotics for the management of bacterial keratitis: an evidence-based review of high quality randomised controlled trials. Br J Ophthalmol. 2014 Nov;98(11):1470-7. doi:

10.1136/bjophthalmol-2013-304660. Consultado el 8 de enero de 2021.

13. Zhen-Yong Zhang, Xing-Ru Zhang. Evaluation of combined riboflavin and ultraviolet A as an alternative treatment for keratitis. Graefes Arch Clin Exp Ophthalmol. 2013 Mar;251(3):9956. doi:10.1007/s00417-012-1950-7. Consultado el 6 de abril de 2020.

14. International Centre for Eye Health (Agosto 2020). https://iceh.lshtm.ac.uk/traditionalmedicine-use-strongly-associated-with-incidence-of-microbial-keratitis/. Consultado el 5 de enero de 2021.

15. José F Ortiz, Sandra P Acevedo, Luis F Restrepo B. Comparación de suero autólogo con un producto comercial como complemento en el tratamiento de úlceras corneales no complicadas en caninos. Revista Colombiana de Ciencias Pecuarias. 2012 Enero-Marzo;25(1). Disponible en: https://www.redalyc.org/pdf/2950/295023572011.pdf. Consultado 3 ed Noviembre de 2020.

16. Traumeel(R) Monografía de producto (2015). Biologische Heilmittel Heel GmbH, Alemania. Tercera edición. Disponible en: https://web.ruizpharma.com/wpcontent/uploads/2018/10/Traumeel_Monografia.pdf

17. Schomlz M, Weiser M. Influence of an antihomotoxic preparation upon the human inmune system. Biol Med 2001; 3:132-5. Consultado el 5 de abril de 2020.

18. Goltwick M. Weizner. Homeopathic therapy of pediatric respiratory infections. Vol 41. No 6,200,pp348-353. Consultado el 5 de abril de 2020.

19. EDUKA HEEL. Vademécum. Disponible en: http://www.edukaheel.com/es/medicamento/157/ubichinon-compositum-ampollas. Consultado el 05 de enero de 2021. 
20. Agencia Española de Medicamentos y Productos Sanitarios Comité de medicamentos

Sacyl.Informe de Posicionamiento Terapéutico de ciclosporina (Ikervis $\left.{ }^{\circledR}\right)$ en el tratamiento de la queratitis grave (2017). Disponible en:

https://www.aemps.gob.es/medicamentosUsoHumano/informesPublicos/docs/IPT-

ciclosporina-Ikervis-ojo-seco.pdf?x54046. Consultado el 18 de enero de 2021.

21. Prednisolona oftálmica. inserto. Disponible en:

http://www.facmed.unam.mx/bmnd/gi_2k8/prods/PRODS/Prednisolona.htm. Consultado el 18 de enero de 2020.

22. Miller E, Fowler M. Zoo and wild animal medicine. Volume 8, El sevier; 2015.

\section{Attachments}




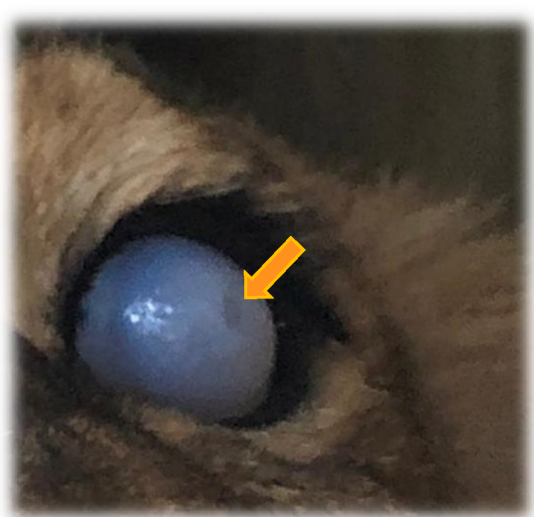

Imagen 1. Opacidad corneal post recuperación corrección quirúrgica

luxación anterior de cristalino y depresión central compatible con úlcera profunda (flecha). $11 \mathrm{de}$ marzo, BW; 2020. 


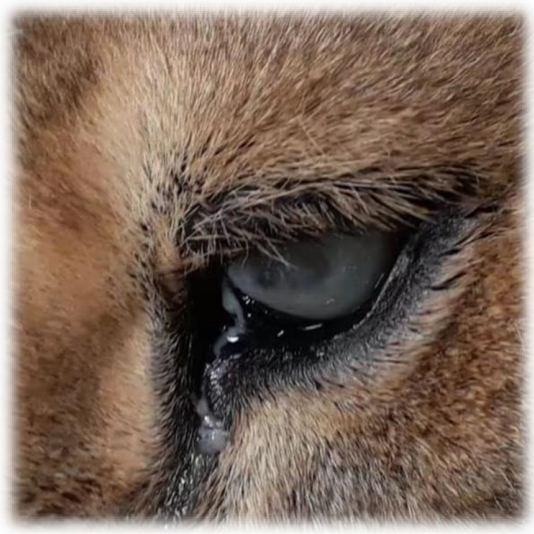

Imagen 2. Secreción mucosa

reportada el 12 de marzo, BW;

2020. 


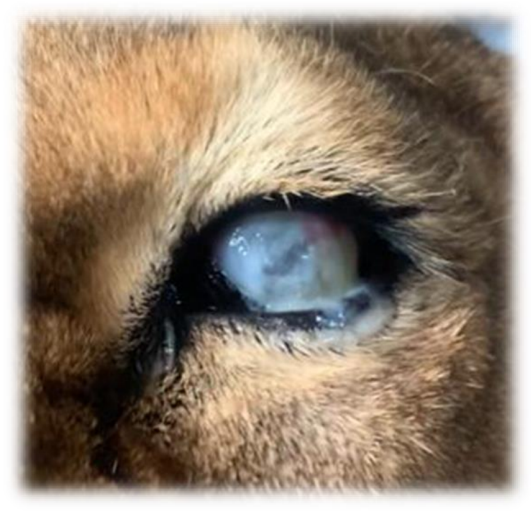

Imagen 3. Secreción

mucopurulenta, mayor opacidad

corneal, neovascularización 23 de

marzo, BW; 2020. 

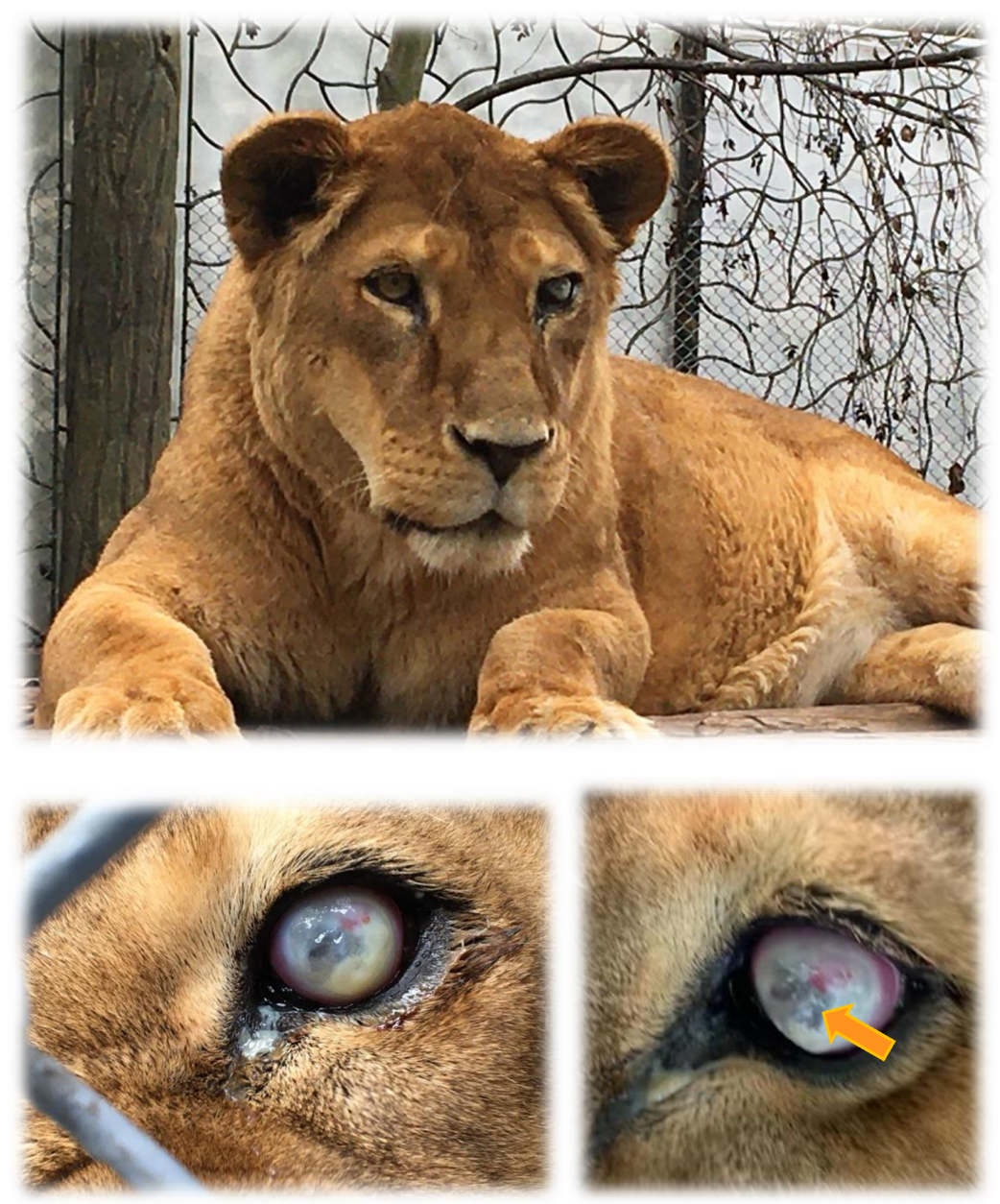

Imagen 4. Valoración presencial y se confirma Queratitis bacteriana complicada por las protuberancias en la córnea y la depresión central (flecha). Fotos tomadas el 25 de marzo, BW;2020

Adicional a la descripción de las imágenes se puede observar la comparación del ojo afectado (izquierdo) con el ojo no afectado (derecho). 


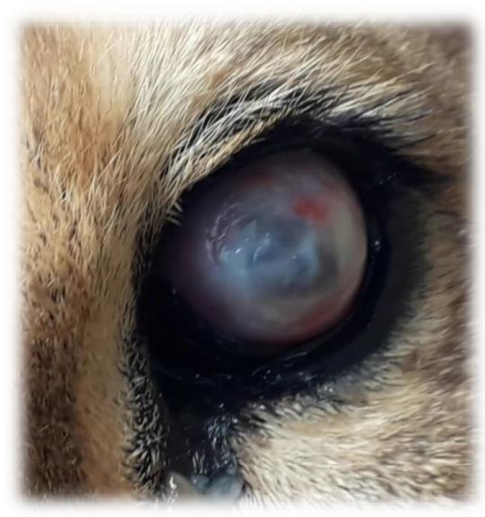

Imagen 5. Día 15: Control del

proceso infeccioso y modulación de

la vascularización. Viene con

tratamiento antibiótico tópico ya

terminó el sistémico, continúa con

Biorreguladores $(0.2 \mathrm{ml}$ Traumeel

ad us. vet. ampollas $+0.2 \mathrm{ml}$

Flamosin compositum ad us. vet.

ampollas $+0.2 \mathrm{ml}$ Placenta

compositum ampollas en a la misma

jeringa del antibiótico BID HNO. 


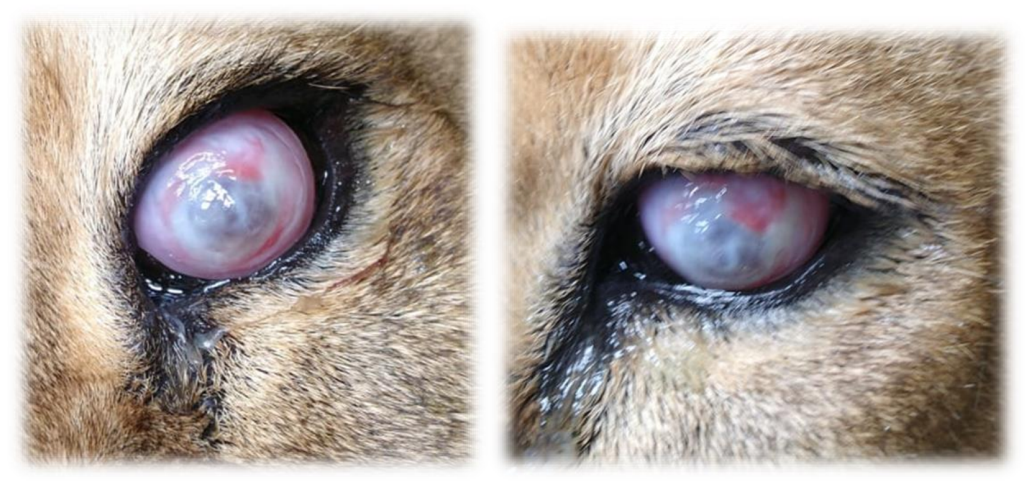

Imagen 6. La queratitis bacteriana está controlada. Se suspende el antibiótico tópico. Continúa sólo con los Biorreguladores y se evidencia una marcada neovascularización en la córnea. 10 de abril, BW; 2020. 


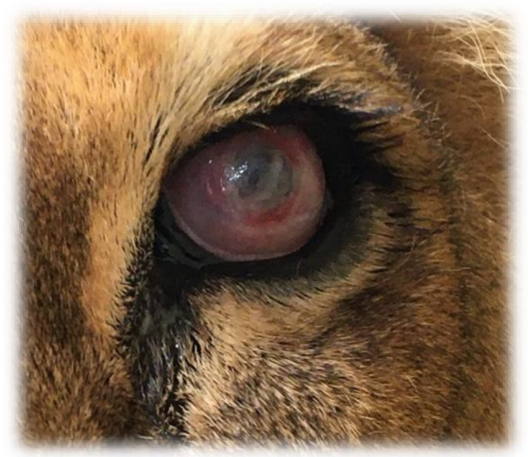

Imagen 7. Día 30: Modulación de la vascularización y proceso

inflamatorio. Viene con tratamiento con Biorreguladores $(0.2 \mathrm{ml}$

Traumeel ad us. vet. ampollas +0.2

$\mathrm{ml}$ Flamosin compositum ad us. vet.

ampollas $+0.2 \mathrm{ml}$ Placenta

compositum ampollas BID HNO.

BW; 2020 . 


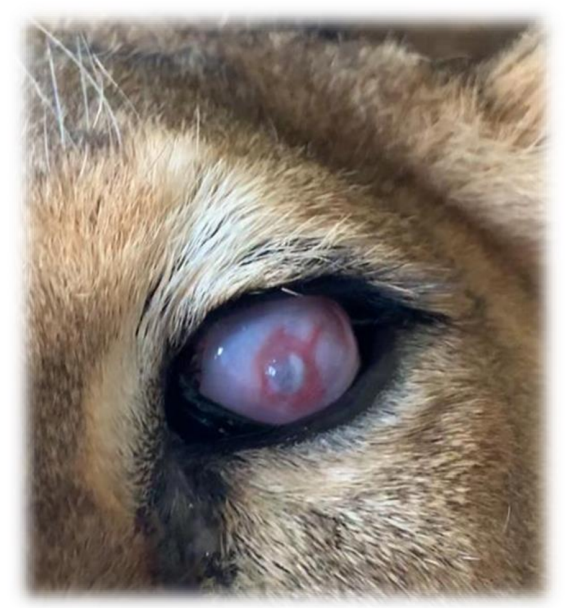

Imagen 8. Día 45: Modulación de la vascularización y migración de los vasos sanguíneos hacia la parte central de la córnea. Tratamiento con Biorreguladores $(0.2 \mathrm{ml}$ Traumeel ad us. vet. ampollas +0.2 $\mathrm{ml}$ Flamosin compositum ad us. vet. ampollas $+0.2 \mathrm{ml}$ Placenta compositum ampollas BID HNO. BW; 2020. 

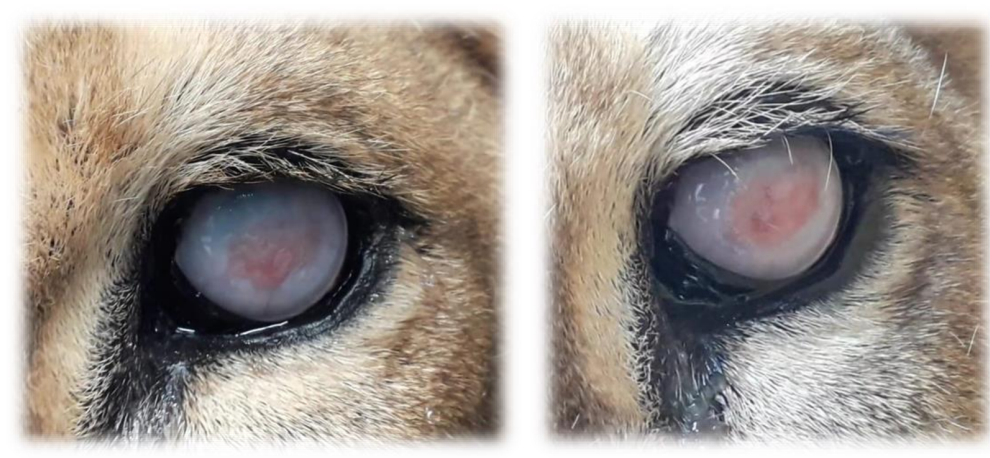

Imagen 9. Día 60: Modulación de la vascularización y migración de los vasos sanguíneos hacia la parte central de la córnea cubriendo por completo con la lesión central que se encontraba irregular y de aspecto débil. Al día siguiente continúa solo con $0.5 \mathrm{ml}$ de Traumeel ad us. vet. ampollas BID X 10 D inicialmente. 25 de abril, BW; 2020. 

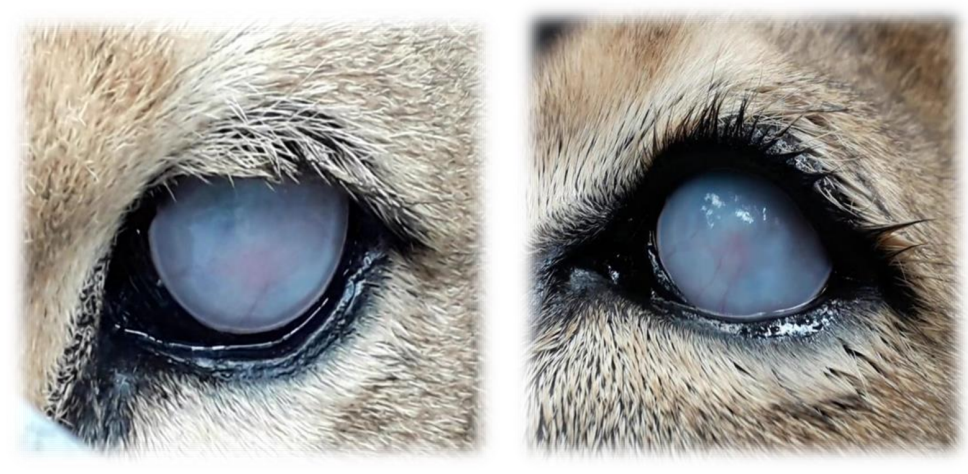

Imagen 10. Día 75: Modulación de la vascularización la cual casi desaparece y remodelación completa de la córnea. Se modifica tratamiento a Traumeel ad us. vet. ampollas $0.5 \mathrm{ml}$ SID HNO. BW; 2020 . 


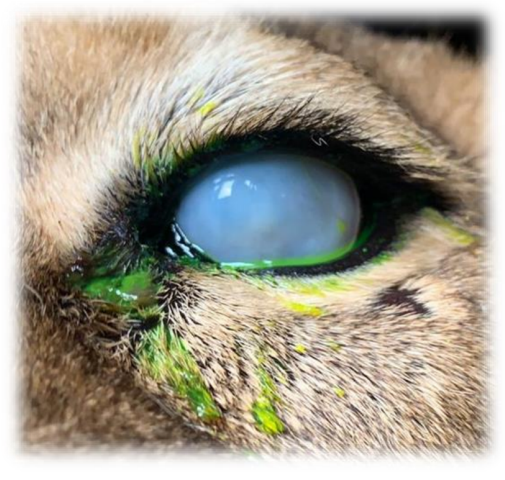

B.

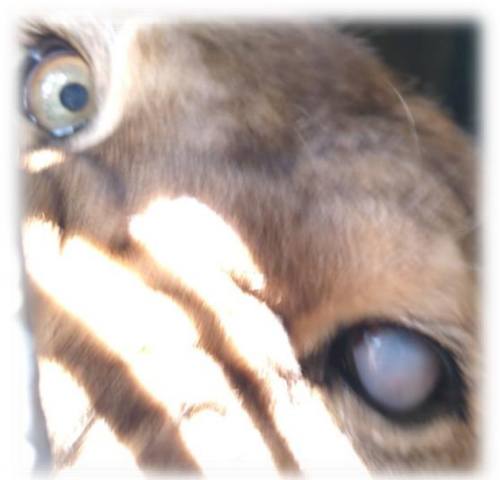

Imagen 11. Día 93: Modulación de la vascularización la cual casi desaparece y córnea totalmente remodelada y lisa. Continúa con Traumeel ad us. vet. ampollas $0.5 \mathrm{ml}$ SID HNO. Fotos tomadas el 03 de Julio antes (B) y después (A) de realizar test de fluoresceína de control el cual resultó negativo para úlcera superficial (A). Se observa también la comparativa con el ojo no afectado (B) (derecho) BW; 2020. 


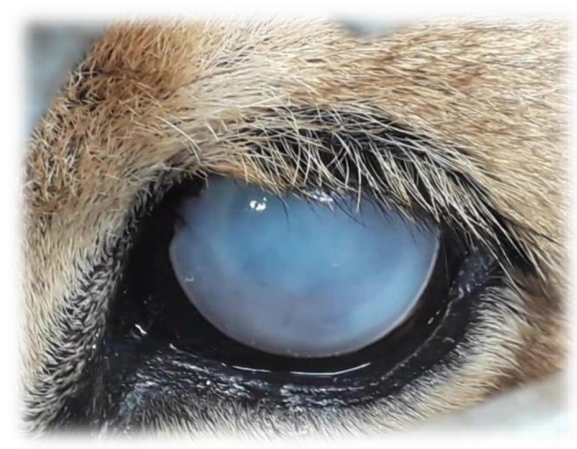

Imagen 12. Día 180: Se evidencia

desaparición de vasos sanguíneos y aclaramiento de la córnea. Continúa con Traumeel ad us. vet. ampollas

$0.5 \mathrm{ml}$ SID HNO. BW; 2020 . 


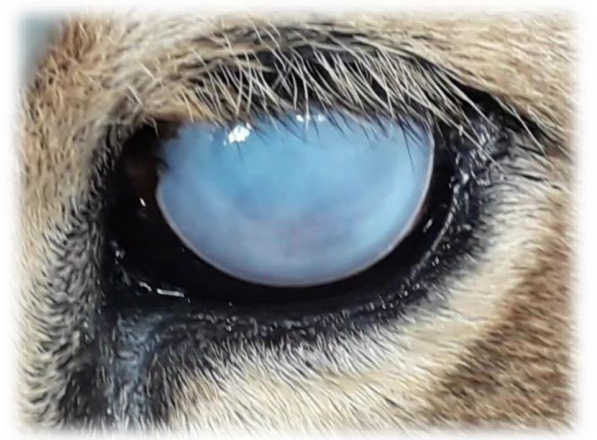

Imagen 13. Día 280: Se observa muy similar al día 180 y está con Traumeel ad us. vet. ampollas $0.5 \mathrm{ml}$ una vez por semana HNO. (Este tratamiento fue modificado en octubre de 2020). Foto tomada el 10 de enero, BW; 2021. 


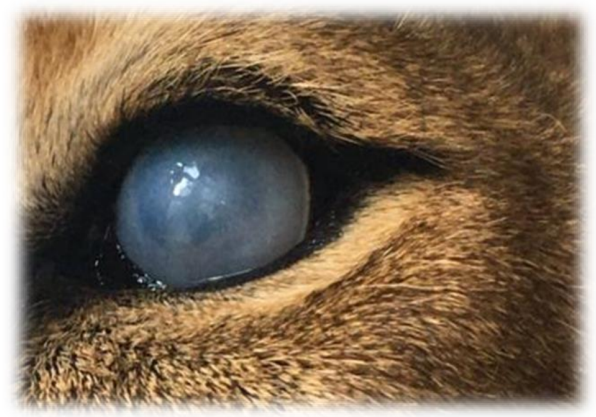

Imagen 14. Día 300: Se evidencia mayor aclaramiento de la córnea desde que se modificó tratamiento Biorregulador suspendiendo el Traumeel e iniciando con $0.2 \mathrm{ml}$ de Gallium-Heel N ampollas $+0.2 \mathrm{ml}$ de Lymphomyosot $\mathrm{N}$ ampollas y $0.2 \mathrm{ml}$ de Ubichinon compositum ampollas en el ojo izquierdo BID $3 \mathrm{~V} x$ sem durante HNO. Foto tomada el 30 de enero, BW; 2021. 